\title{
NEW RELIABILITY SCORE FOR COMPONENT STRENGTH USING KULLBACK-LEIBLER DIVERGENCE
}

\section{NOWA METODA OCENY NIEZAWODNOŚCI NA PODSTAWIE WYTRZYMAŁOŚCI ELEMENTÓW Z ZASTOSOWANIEM DYWERGENCJI KULLBACKA-LEIBLERA}

\begin{abstract}
The reliability of technical systems is one of the most important research subjects in the point reached by modern science. In many recent studies, this problem is solved by evaluation the operation performance of determined one or more components operating under stress. At this point, $R=P(X<Y)$ is taken as a basis. Here, $X$ is the stress applied on the operating component and $Y$ is the strength of the component. In this study we aim to propose a new method by using Kullback-Leibler divergence for computing the reliability of the component under stress-strength model. The superiority of the proposed method is that when the component durability is equal to applied stress Kullback-Leibler divergence is equal to zero. In addition to that when more than one stresses exists at the same time the formed function can include all stresses at the same time. When $R$ is used, this is not possible because of stresses are evaluated separately. As Kullback-Leibler divergence is calculated depending on time, the strength of the component is evaluated within a dynamic structure.
\end{abstract}

Keywords: reliability, stress-strength model, multistate system model, Kullback-Leibler divergence.

\begin{abstract}
Niezawodność systemów technicznych jest jednym z najważniejszych tematów badawczych we wspótczesnej nauce. Wiele z ostatnich badań, problem ten rozwiazuje poprzez ocenę wydajności pracy jednego lub większej liczby wybranych elementów działających pod wptywem obciażenia. Za punkt wyjściowy przyjmuje się $R=P(X<Y)$. X to obciażenie przyłożone do elementu roboczego, a Y to wytrzymatość elementu. W przedstawionej pracy, chcemy zaproponować nowa metode, w której do obliczania niezawodności elementu w ramach modelu typu "obciązenie-wytrzymałość" wykorzystuje się dywergencję Kullbacka-Leiblera. Proponowana metoda ma te przewage, że gdy wytrzymałość elementu jest równa przyłożonemu obciażeniu, dywergencja Kullbacka-Leiblera jest równa zeru. Poza tym, gdy jednocześnie występuje więcej niż jeden rodzaj obcią̇enia, utworzona funkcja może obejmować jednocześnie wszystkie te obciażenia. Nie jest to możliwe przy zastosowaniu R, ponieważ obciążenia sq oceniane oddzielnie. Ponieważ dywergencję Kullbacka-Leiblera oblicza się w funkcji czasu, wytrzymałość elementu ocenia się w strukturze dynamicznej.
\end{abstract}

Stowa kluczowe: niezawodność, model typu obciażenie-wytrzymałość, model systemu wielostanowego, dywergencja Kullbacka-Leiblera.

\section{Introduction}

All technical systems have been designed to perform their intended tasks in a specific ambient. Some systems can perform their tasks in a variety of distinctive levels. A system that can have a finite number of performance rates is called a multi-state system. Generally multi-state system is consisted of components that they also can be multi-state. The performance rates of components can also vary as a result of their deterioration or in consequence of variable environmental conditions. Components failure can lead to the degradation of the entire multi-state system performance.

The performance rates of the components can range from perfect functioning up to complete failure. The quality of the system is completely determined by components.

In some cases, the status of the system depends on the effect of several stresses which cause degradation. The system may not fail fully, but can degrade and there may exist several states of the system. This situation corresponds to multistate systems. For an excellent review of multistate system we refer to Andrzejczak [1]. Indeed, a binary system is the simplest case of a multi-state system having two distinguished states; perfect functioning and completely failure. In a binary system, the definition domains of the states of the system and its components are $\{0,1\}$.
Multi-state systems have been found to be more flexible tool than binary systems for modeling engineering systems. In literature, much attention has been paid to multi-state system modeling. El-Neweihi et al. [14] provided axioms extending the standard notion of a coherent system to the new notion of a multistate coherent system. For such systems they obtained deterministic and probabilistic properties for system performance which are analogous to well- known results for coherent system reliability. Hudson and Kapur [19] presented some models and their applications, in terms of reliability analyses, to situations where the system and all its components have a multiple states. Ebrahimi [11] proposed two types of multistate coherent system and presented various properties related to them. Brunella and Kapur [7] studied a series of reliability measures and expanded their definitions to be consisted with binary, multistate and continuum models. Kuo and Zuo [22] focused on multistate system reliability models and introduced several special multistate system reliability models. Eryılmaz [15] studied mean residual and mean past lifetime concepts for multistate systems. Also, for more details about multi-state system model one can see Andrzejczak [2] and [3].

For reliability analysis, stress-strength models are of special importance. In the simplest terms, stress-strength model can be described as an assessment of the reliability of the component in terms of $X$ and $Y$ random variables where $X$ is the random "stress" experienced by the 
component and $Y$ is the random "strength" of the component available to overcome the stress. From this simplified explanation, the reliability of the component is the probability that the component is strong enough to overcome the stress applied on it. Then the reliability of the system is defined as:

$$
P(X<Y)=\int_{0}^{\infty} F(x) d G(x)
$$

where $F(x)$ and $G(x)$ are distribution functions of $X$ and $Y$, respectively. Also, for $x<0, F(x)=G(x)=0$.

Extensive works have been done for the reliability of the component and its estimation under different choices for stress and strength distributions. Chandra and Owen [8] studied the estimation of the reliability of a component where component is subject to several stresses whereas its strength is a single random variable. Awad and Gharraf [4] used a simulation study which compares minimum variance unbiased estimator, the maximum likelihood estimator and bayes estimator for $R$ when $X$ and $Y$ are two independent but not identically distributed Burr random variables. Kotz et al. [20] presented comprehensive information about all methods and results on the stress-strength model. Nadarajah and Kotz [24] calculated $R$ when $X$ and $Y$ are independent random variables from six flexible families of bivariate exponential distributions. Eryılmaz and İşçioğlu [16] studied multi-state systems in a stress-strength setup.

Traditionally, stress and strength random variables are considered to be both static when available data on $X$ and $Y$ are considered not to involve the time of system operation. But in real-life reliability studies, the status of a stress-strength system clearly changes dynamically with time. In many important applications, it is very necessary that we estimate the reliability of the system without waiting to observe the system failure. This problem may be achieved by modeling at least one of the stress or strength quantities as time-dependent. To pay attention this problem, Basu and Ebrahimi [5] defined the random lifetime $T$, of the system as:

$$
T=\inf \{t: t \geq 0, Y(t) \leq X(t)\}
$$

where $X(t)$ and $Y(t)$ denote the stress that the system is experiencing at time $t$ and strength at time $t$, respectively. For a specific time period $\left(0, t_{0}\right)$, the reliability of a stress-strength system, $R\left(t_{0}\right)$, which is defined as the probability of surviving at time $t_{0}$, follows from (2) that:

$$
R\left(t_{0}\right)=P\left(T>t_{0}\right)
$$

Reliability of a stress-strength system is a function of time. This function has been studied in several papers. Ebrahimi [12] investigated this dynamic model on condition that the strength of the system $Y(t)$ is decreasing in time. Whitmore [28], Ebrahimi and Ramallingam [13], Basu and Lingham [6] considered the problem of estimating the reliability of a system when both $X(t)$ and $Y(t)$ are assumed to be independent Brownian motion processes.

In this paper, inspired by the idea of Kullback-Leibler (KL) divergence, we aim to propose a new method for computing the reliability of the component under stress-strength model. The proposed method provides a simple way for determining the component operation performance under more than one stresses depending on time.

The rest of this paper is organized as four sections. Section 2 gives some information and properties about KL divergence. In Section 3, we explain the proposed method for evaluation of the component's performance under the stress-strength model. Section 4 contains some examples to show the usefulness of the proposed method for different marginal lifetime distributions of the stress and strength random variables. In Section 5, we summarize what we have done in the article and give some conclusions.

\section{2. $\mathrm{KL}$ divergence and properties}

The KL divergence (or relative entropy) which introduced by Kullback and Leibler [21], measures the distance between the distributions of random variables. If the densities $p(x)$ and $q(x)$ of $P$ and $Q$, respectively, exist with respect to Lebesque measure, the KL divergence $D_{K L}(P \| Q)$ of $Q$ from $P$ is defined as:

$$
D_{K L}(P \| Q)=\int_{S} p(x) \log \frac{p(x)}{q(x)} d x,
$$

where $S$ is the support set of $p(x)$. Note that, $D_{K L}(P \| Q)$ is finite only if $P$ is absolutely continuous with respect to $Q$, and $+\infty$ otherwise. Importantly, the KL divergence remains non-negative and is known as Gibbs' inequality and is zero if and only if $P=Q$, i.e., for any two distributions $P$ and $Q$ :

$$
D_{K L}(P \| Q) \geq 0
$$

Note that it is not a symmetrical quantity, that is to say:

$$
D_{K L}(P \| Q) \not \equiv D_{K L}(Q \| P) .
$$

In information theory, machine learning and statistics, the KL divergence plays an important role. The applications of its can be found in many areas. In literature, much attention has been paid to it. Hall [18] examined Discrimination Information or KL loss in the context of nonparametric kernel density estimation. Also, he showed that its asymptotic properties are profoundly influenced by tail properties of the kernel and of the unknown density. Dahlhaus [9] calculated the asymptotic KL information divergence of two locally stationary sequences and the limit of the Fisher information matrix. Do [10] proposed a fast algorithm to approximate the KL distance between two hidden Markov models. Rached et al. [25] provided an explicit computable expression for the KL divergence rate between two arbitrary time-invariant finite-alphabet Markov sources. Wang et al. [27] proposed a universal divergence estimator for absolutely continuous distributions $P$ and $Q$ based on independent and identically distributed samples generated from each source. In Markov-switching regression models, Smith et al. [26] used KL divergence between the true and candidate models to select the number of states and variables simultaneously. Lee and Park [23] considered estimation of the KL divergence between the true density and a selected parametric model.

\section{Proposed method}

In this section, we introduce a new approach for determining the component operation performance where component is subject to $X_{1}(t), X_{2}(t), \ldots, X_{\mathrm{n}}(t)$ stresses, whereas its strength, $Y(t)$, is a single random process. Let us initially assume that the stresses are independent random processes having continuous cumulative distribution functions $F_{\xi}^{t}(x)=P\left\{X_{\xi}(t) \leq x\right\}, \xi=1,2, \ldots, \mathrm{n}$ and the strength has the marginal distribution function $G^{t}(x)=P\{Y(t) \leq x\}$.

In our method, we first form the KL divergence $D_{K L}\left(Y(t) \| X_{\xi}(t)\right)=D_{K L(\xi)}^{(t)}$ of $\mathrm{X}_{\xi}(\mathrm{t})$ from $\mathrm{Y}(\mathrm{t})$ by using (3) for $\xi=1,2, \ldots$, n. After this, we calculate the $D_{K L(\xi)}^{(t)}$, for selected values of the parameters of marginal lifetime distributions of the stress and 
strength random variables. Using these values the operation level of the component, depending on the number of stresses, can be defined as follows:

$$
\text { The level of the }:\left\{\begin{array}{lc}
n, & t<t_{n} \\
n-1, & t_{n} \leq t<t_{n-1} \\
n-2, & t_{n-1} \leq t<t_{n-2} \\
\vdots & \vdots \\
2, & t_{3} \leq t<t_{2} \\
1, & t_{2} \leq t<t_{1} \\
0, & t_{1} \leq t
\end{array}\right.
$$

where $t_{\xi}$ denotes the time when $D_{K L(\xi)}^{(t)}$ is equal to zero, $\xi=1,2, \ldots, \mathrm{n}$. Also using $D_{K L(\xi)}^{(t)}$ and $t_{\xi}$ values we can define the following equations:

$$
\zeta_{t}^{v}=\left\{\begin{array}{cc}
D_{K L(v)}^{(t)}, & t_{v+1}<t \leq t_{v} \\
0, & \text { otherwise }
\end{array}\right.
$$

where $v=1,2, . ., n-1$ and:

$$
\zeta_{t}^{n}=\left\{\begin{array}{c}
D_{K L(n)}^{(t)}, \quad t \leq t_{n} \\
0, \quad \text { otherwise }
\end{array}\right.
$$

Now with the help of the above equations, the new reliability score $\Upsilon(t)$ for the component can be expressed as follows:

$$
\Upsilon(t)=\sum_{j=1}^{n} \chi_{t}^{j}\left(j-1+\frac{\zeta_{t}^{j}}{u_{j}}\right)
$$

where:

$$
\chi_{t}^{j}=\left\{\begin{array}{l}
1, \quad \zeta_{t}^{j}>0 \\
0, \quad \zeta_{t}^{j}=0
\end{array}\right.
$$

and $u_{j}=\sup D_{K L(j)}^{(t)}$.

In probabilistic design it is common to use parametric statistical models to compute the reliability obtained from stress-strength interference theory. In the following section we apply our method to a Weibull distributional example.

\section{A Weibull distributional example}

In this section, we apply the proposed method to find the component operation performance. Assume that the component is subject to $X_{1}(t), X_{2}(t)$ and $X_{3}(t)$ stresses, which remain fixed over time, whereas its strength, $Y(t)$, is a single random variable, which is stochastically decreasing in time.
A Weibull process is a useful model for events that are changing over time. Here, let $G$ be a Weibull cumulative distribution function and its shape parameter $\beta>0$ is constant with aging time, while its scale parameter $\alpha(t)$ decreases over time.

Then, its cumulative distribution function can be written as:

$$
G^{t}(x)=1-\exp \left\{-\left(\frac{x}{\alpha(t)}\right)^{\beta}\right\}, x>0
$$

Similarly, assume that $X_{1}, X_{2}$ and $X_{3}$ are Weibull random variables with cumulative distribution functions:

$$
F_{l}(x)=1-\exp \left\{-\left(\frac{x}{\theta_{l}}\right)^{\beta}\right\}, x>0,
$$

where $\beta>0$ is the shape parameter, $\theta_{l}>0$ is the scale parameter of the distributions and $l=1,2,3$. Also both $\beta$ and $\theta_{l}$ are constant with aging time.

For computing the operation performance of a component at first we must form KL divergence $D_{K L(l)}^{(t)}$ of $X_{l}$ from $Y(t)$ for $l=1,2,3$. The KL divergence (3) can also be written for $X_{l}(l=1,2,3)$ and $Y(t)$ as:

$$
D_{K L(l)}^{(t)}=H\left(y, x_{l}\right)-H(y)
$$

where:

$$
H\left(y, x_{l}\right)=\int g_{t}(x) \log \frac{1}{f_{l}(x)} d x
$$

and:

$$
H(y)=\int g_{t}(x) \log \frac{1}{g_{t}(x)} d x
$$

Here, $H(y)$ is the differential entropy of a continuous random variable $Y(t)$ with density $g_{t}(x)$. Let $Y(t), X_{1}, X_{2}$ and $X_{3}$ are independent. Now, using probability density functions of (5) and (6) in (8), we have:

$$
\begin{aligned}
& H\left(y, x_{l}\right)=-\int_{0}^{\infty} \frac{\beta}{[\alpha(t)]^{\beta}} x^{\beta-1} e^{-\left(\frac{x}{\alpha(t)}\right)^{\beta}} \log \left(\frac{\beta}{\left(\theta_{l}\right)^{\beta}} x^{\beta-1} e^{-\left(\frac{x}{\theta_{l}}\right)^{\beta}}\right) d x
\end{aligned}
$$

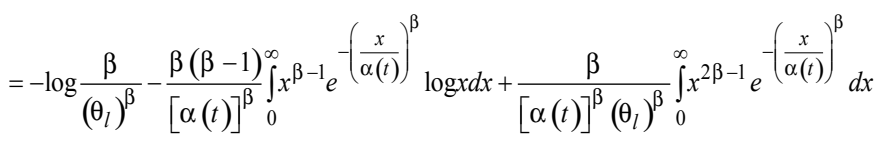

By making the substitution $u=\left(\frac{x}{\alpha(t)}\right)^{\beta}$ in (10) and then using following integral:

$$
\int_{0}^{\infty} e^{-t} \log t d t=-C
$$


where $\mathrm{C} \approx 0.577215$ is the Euler's constant ( Eq. 8.367.4 in Gradshteyn and Ryzhik, [17]), $H\left(y, x_{l}\right)$ can be obtained as:

$$
H\left(y, x_{l}\right)=-\log \frac{\beta}{\left(\theta_{l}\right)^{\beta}}+(\beta-1)\left(\frac{C}{\beta}-\log \alpha(t)\right)+\left(\frac{\alpha(t)}{\theta_{l}}\right)^{\beta} .
$$

Similarly, using probability density function of (5) in (9), we have:

$$
H(y)=-\log \frac{\beta}{[\alpha(t)]^{\beta}}+(\beta-1)\left(\frac{C}{\beta}-\log \alpha(t)\right)+1
$$

where suitable transformations and simplifications have been applied and also (11) used.

Table 1. Numerical values obtained from Equation (15) for $\beta=0.9, \theta_{1}=0.01$, $\theta_{2}=0.02$ and $\theta_{3}=0.05$

\begin{tabular}{|c|l|l|l||}
\hline$t$ & $D_{K L(1)}^{(t)}$ & $D_{K L(2)}^{(t)}$ & $D_{K L(3)}^{(t)}$ \\
\hline 5 & 11.126 & 4.870 & 1.234 \\
\hline 10 & 4.870 & 1.808 & 0.242 \\
\hline 15 & 2.807 & 0.871 & 0.036 \\
\hline 20 & 1.808 & 0.456 & 0. \\
\hline 25 & 1.234 & 0.242 & 0.018 \\
\hline 30 & 0.871 & 0.123 & 0.059 \\
\hline 35 & 0.627 & 0.057 & 0.107 \\
\hline 40 & 0.456 & 0.021 & 0.159 \\
\hline 45 & 0.333 & 0.004 & 0.211 \\
\hline 50 & 0.242 & 0. & 0.263 \\
\hline 55 & 0.174 & 0.003 & 0.312 \\
\hline 60 & 0.123 & 0.012 & 0.360 \\
\hline 65 & 0.085 & 0.025 & 0.406 \\
\hline 70 & 0.057 & 0.041 & 0.451 \\
\hline 75 & 0.036 & 0.059 & 0.493 \\
\hline 80 & 0.021 & 0.078 & 0.534 \\
\hline 85 & 0.011 & 0.097 & 0.574 \\
\hline 90 & 0.004 & 0.118 & 0.611 \\
\hline 95 & 0.001 & 0.138 & 0.648 \\
\hline 100 & 0. & 0.159 & 0.683 \\
\hline & & & \\
\hline \hline
\end{tabular}

Now using (12) and (13) in (7) we have:

$$
D_{K L(l)}^{(t)}=\log \left(\frac{\theta_{l}}{\alpha(t)}\right)^{\beta}+\left(\frac{\alpha(t)}{\theta_{l}}\right)^{\beta}-1 .
$$

Because of $\alpha(t)$ decreases over time, in (14), let $\alpha(t)=1 / t$ then we have:

$$
D_{K L(l)}^{(t)}=\log \left(t \theta_{l}\right)^{\beta}+\left(\frac{1}{t \theta_{l}}\right)^{\beta}-1
$$

where $l=1,2,3$.

Clearly, when values in Table 1 used, we have:

$$
\text { The level of the } \begin{cases}3, & t<t_{3} \\ 2, & t_{3} \leq t<t_{2} \\ 1, & t_{2} \leq t<t_{1} \\ 0, & t_{1} \leq t\end{cases}
$$

where $t_{1}=100, t_{2}=50$ and $t_{3}=20$. Then, for $n=3$ in (4), we have:

$$
\Upsilon(t)=\chi_{t}^{1}\left(\frac{\zeta_{t}^{1}}{u_{1}}\right)+\chi_{t}^{2}\left(1+\frac{\zeta_{t}^{2}}{u_{2}}\right)+\chi_{t}^{3}\left(2+\frac{\zeta_{t}^{3}}{u_{3}}\right),
$$

where $u_{l}=\sup D_{K L(l)}^{(t)} ; l=1,2,3$,

$\zeta_{t}^{1}=\left\{\begin{array}{cc}D_{K L(1)}^{(t)}, & 50<t \leq 100 \\ 0, & \text { otherwise }\end{array} ; \zeta_{t}^{2}=\left\{\begin{array}{cc}D_{K L(2)}^{(t)}, & 20<t \leq 50 \\ 0, & \text { otherwise }\end{array} ; \zeta_{t}^{3}=\left\{\begin{array}{cc}D_{K L(3)}^{(t)}, & t \leq 20 \\ 0, & \text { otherwise }\end{array}\right.\right.\right.$,

and:

$$
\chi_{t}^{1}=\left\{\begin{array}{l}
1, \quad \zeta_{t}^{1}>0 \\
0, \zeta_{t}^{1}=0
\end{array} ; \chi_{t}^{2}=\left\{\begin{array}{l}
1, \quad \zeta_{t}^{2}>0 \\
0, \quad \zeta_{t}^{2}=0
\end{array} ; \chi_{t}^{3}=\left\{\begin{array}{l}
1, \zeta_{t}^{3}>0 \\
0, \quad \zeta_{t}^{3}=0
\end{array} .\right.\right.\right.
$$

Finally, using (16) for $t=5,10, . ., 100$ we can obtain the new reliability score presented in Table 2 for the component under stress-strength setup.

It can be observed from numerical values in Table 1 how stresses affect the performance of the component that operates under different parameters. When the component starts working, its strength is greater than all stresses. However, because the component's strength is decreasing depending on the selected time, as the uptime increases at first the KL divergence $D_{K L(3)}^{(t)}$ decreases to near zero. In this period, the strength of the component will begin to move to the good position declined from a perfect position. From the moment that $D_{K L(3)}^{(t)}=0$, the component will pass to the good working period from a perfect working period, the KL divergence $D_{K L(3)}^{(t)}$ is not considered and instead of the KL divergence $D_{K L(2)}^{(t)}$ is taken into account. The KL divergence $D_{K L(2)}^{(t)}$ will be reduced again depending on the time. From the moment it is equal to zero, the component will pass to the average working period from a good working period, the KL divergence $D_{K L(2)}^{(t)}$ is not considered and instead of the KL divergence $D_{K L(1)}^{(t)}$ is taken into account. The KL divergence $D_{K L(1)}^{(t)}$ will be reduced again depending on the time. From the moment it is equal to zero, the operation of the component will end and because the component's durability remains weak in three stresses the component will be impaired.

In stress-strength model which is designed as a theoretically, when the component's strength remains weak in three stresses the component is fail. Let us consider all stresses, by using (1), a joint reliability is not calculated but instead the reliability is calculated separately according to the stresses. 
Table 2. New reliability score for the component when $\beta=0.9, \theta_{1}=0.01$, $\theta_{2}=0.02$ and $\theta_{3}=0.05$

\begin{tabular}{|c|c|c|c||}
\hline$t$ & $\Upsilon(t)$ & $t$ & $\Upsilon(t)$ \\
\hline 5 & 3. & 55 & 0.0156 \\
\hline 10 & 2.1961 & 60 & 0.0110 \\
\hline 15 & 2.0291 & 65 & 0.0076 \\
\hline 20 & 2. & 70 & 0.0051 \\
\hline 25 & 1.0496 & 75 & 0.0032 \\
\hline 30 & 1.0252 & 80 & 0.0018 \\
\hline 35 & 1.0117 & 85 & 0.0009 \\
\hline 40 & 1.0043 & 90 & 0.0003 \\
\hline 45 & 1.0008 & 95 & 0.00008 \\
\hline 50 & 1. & 100 & 0. \\
\hline
\end{tabular}

\section{Conclusion}

In the study, it is theoretically assumed that a component operates under $n$ different stresses and when the component's strength remains weak in all stresses the component is fail. Here, for reliability evaluation we provide a new approach for obtaining the component operation performance. The proposed method described here is a simple and can clearly show the chance of component operation performance depending on time while under all stresses. The evaluation of the component operation performance naturally depends on the probability distributions of stresses and selection of probability distribution of component strength. The method used in the study does not originally depend on probability distribution. Reliability function is a parametric method, but the reliability score proposed from this aspect is nonparametric method for the component. When different effect functions are used instead of probability functions of stress and strength, the recommended method can be easily used.

\section{References}

1. Andrzejczak K. Some properties of multistate BW-systems. Serdica Bulgaricae Mathematicae Publicationes 1987; 13: 341-346.

2. Andrzejczak K. Deterministic properties of the multistate systems. Proceedings of the Fifth Anniversary International Conference RELCOMEX'89, Poland, Książ Castle, September. 1989; 25-32.

3. Andrzejczak K. Structure analysis of multistate coherent systems. Optimization 1992; 25: 301-316, http://dx.doi. org/10.1080/02331939208843826.

4. Awad A M, Gharraf M K. Estimating of $\mathrm{P}(\mathrm{Y}<\mathrm{X})$ in the Burr case: A comparative study. Commun. Statist. Simul. Computat. 1986; 15:189403, http://dx.doi.org/10.1080/03610918608812514.

5. Basu A P, Ebrahimi N. On the reliability of stochastic systems. Statist. Probab. Lett. 1983; 1: 265-267, http://dx.doi.org/10.1016/01677152(83)90042-1.

6. Basu S, Lingham R T. Bayesian estimation of system reliability in Brownian stress-strength models. Ann. Inst. Statist. Math. 2003; 55: 7-19, http://dx.doi.org/10.1007/BF02530482.

7. Brunelle R D, Kapur K C. Review and classification of reliability measures for multistate and continuum models. IIE Transactions 1999; 31 : 1171-1180, http://dx.doi.org/10.1080/07408179908969917.

8. Chandra S, Owen D B. On estimating the reliability of a component subject to several different stresses (strengths). Naval Res. Log. Quart. 1975; 22: 31-40, http://dx.doi.org/10.1002/nav.3800220104.

9. Dahlhaus R. On Kullback-Leibler information divergence of locally stationary processes. Stoch. Process. Appl. 1996; 62: 139-168, http:// dx.doi.org/10.1016/0304-4149(95)00090-9.

10. Do M N. Fast approximation of Kullback-Leibler distance for dependence trees and hidden Markov models. IEEE Signal Processing Lett. 2003; 10: 115-118, http://dx.doi.org/10.1109/LSP.2003.809034.

11. Ebrahimi N. Multistate reliability models. Naval Research Logistics Quarterly 1984; 31: 671-680, http:/dx.doi.org/10.1002/ nav.3800310415.

12. Ebrahimi N. Two suggestions of how to define a stochastic stress-strength system. Statist. Probab. Lett. 1985; 3: 295-297, http://dx.doi. org/10.1016/0167-7152(85)90058-6.

13. Ebrahimi N. Ramallingam T. Estimation of system reliability in Brownian stress-strength models based on sample paths. Ann. Inst. Statist. Math. 1993; 45: 9-19, http://dx.doi.org/10.1007/BF00773665.

14. El-Neweihi E, Proschan F, Sethuraman J. Multi-state coherent system. Journal of Applied Probability 1978; 15: 675-688, http://dx.doi. org/10.2307/3213425

15. Ery1lmaz S. Mean Residual and Mean Past Lifetime of Multi-State Systems With Identical Components. IEEE Trans. Reliab. 2010; 59: 644649, http://dx.doi.org/10.1109/TR.2010.2054173.

16. Eryılmaz S, İşçioğlu F. Reliability evaluation for a multi-state system under stress-strength setup. Commun. Statist. Theor. Meth. 2011; 40: 547-558, http://dx.doi.org/10.1080/03610920903411242.

17. Gradshteyn I S, Ryzhik I M. Table of Integrals, Series and Products. 6th ed. California: Academic Press, 2000.

18. Hall P. On Kullback-Leibler loss and density estimation. Ann. Statist. 1987; 15: 1491-1519, http://dx.doi.org/10.1214/aos/1176350606.

19. Hudson J C, Kapur K C. Reliability analysis for multistate systems with multistate components. IIE Transactions 1983; 15: 127-135, http:// dx.doi.org/10.1080/05695558308974623.

20. Kotz S, Lumelskii Y, Pensky M. The Stress-Strength Model and its Generalizations. Theory and Applications. Singapore: World Scientific, 2003, http://dx.doi.org/10.1142/9789812564511.

21. Kullback S, Leibler R A. On information and sufficiency. Ann. Math. Statist. 1951; 22: 79-86, http://dx.doi.org/10.1214/aoms/1177729694.

22. Kuo W, Zuo M J. Optimal Reliability Modeling, Principles and Applications. New York: John Wiley \& Sons, 2003. 23, Lee Y K, Park B U. Estimation of Kullback-Leibler divergence by local likelihood. Ann. Inst. Statist. Math. 2006; 58: 327-340.

23. Lee Y K, Park B U. Estimation of Kullback-Leibler divergence by local likelihood. Ann. Inst. Statist. Math. 2006; 58: 327-340.

24. Nadarajah S, Kotz S. Reliability for some bivariate exponential distributions. Mathematical Problems in Engineering 2006; 2006: 1-14, http://dx.doi.org/10.1155/mpe/2006/41652.

25. Rached Z, Alajaji F, Lorne Campbell L. The Kullback-Leibler Divergence Rate Between Markov Sources. IEEE Trans. Inform. Theory 
2004; 50: 917-921, http://dx.doi.org/10.1109/TIT.2004.826687.

26. Smith A, Naik P A, Tsai C L. Markov-switching model selection using Kullback-Leibler divergence. Journal of Econometrics 2006; 134: 553-577, http://dx.doi.org/10.1016/j.jeconom.2005.07.005.

27. Wang Q, Kulkarni S, Verdú S. Divergence Estimation of Continuous Distribution based on data-dependent Partitions. IEEE Trans. Inform. Theory 2005; 51: 3064-3074, http://dx.doi.org/10.1109/TIT.2005.853314.

28. Whitmore G A. On the reliability of stochastic systems: a comment. Statist. Probab. Lett. 1990; 10: 65-67, http://dx.doi.org/10.1016/01677152(90)90113-L.

\section{Gökhan GÖKDERE}

Mehmet GÜRCAN

Department of Statistics, Faculty of Science

Firat University, TR-23119 Elazığ, Turkey

E-mails: g.g.gokdere@gmail.com, mehmetgurcan2000@yahoo.com 